\title{
Adolescência e relações amorosas: um estudo sobre jovens das camadas populares cariocas
}

\author{
Mariana Matos \\ Terezinha Féres-Carneiro \\ Bernardo Jablonski \\ Pontifícia Universidade Católica do Rio de Janeiro
}

\begin{abstract}
RESUMO
O presente estudo buscou investigar a adolescência, focalizou as concepções e vivências das relações amorosas de indivíduos, neste período do desenvolvimento, pertencentes às chamadas camadas populares do Rio de Janeiro, o que se deu através de entrevistas semi-estruturadas, cujos temas incluíam o envolvimento em namoros, relacionamentos esporádicos como "ficar", manifestações da sexualidade, perspectivas futuras de casamento e formação de família. Utilizando-se como referencial teórico básico os autores da abordagem psicanalítica, realizou-se, inicialmente, uma revisão sobre o conceito de adolescência e as características desta fase do desenvolvimento. Em seguida, abordou-se o tema das relações amorosas, subdividido em uma revisão sobre sua evolução através dos tempos, seguida de um levantamento de dados encontrados em pesquisas recentes e considerações sobre as novas formas de relacionamentos. Finalmente, foram apresentados e discutidos os resultados da pesquisa de campo realizada, que apontou para o desejo, por parte dos adolescentes entrevistados, de relações duradouras, com envolvimento afetivo, possibilitadas através do "ficar", que proporciona o maior conhecimento do parceiro desejado.
\end{abstract}

Palavras-chave: adolescência; classes populares; relações amorosas; "ficar".

\begin{abstract}
Adolescence and love relationships: a study of Rio de Janeiro's lower class teenagers

On the present study the conceptions and experiences of love relationships, among lower class teenagers from Rio de Janeiro, were investigated. A semi-structured interview was used, including themes such as dating, flirting, and perspectives on future marriage and family formation. First, a review of adolescence as a theoretical construct was realized in the psychoanalytical literature, including its developmental characteristics, and then, love relations were reviewed following its transformation throughout history. The major research findings were and compared to contemporary forms of romantic relationships. Finally, the results of the present study were presented and discussed. Results stressed teenagers desire for long-term relationships, based on mutual affect, specially made possible through the "ficar" relationship, that means flirting, in which partners could increase their mutual knowledge.
\end{abstract}

Keywords: adolescence; lower-class teenagers; love relationships; dating.

A vida amorosa dos jovens dos tempos atuais é bastante diferente da vivida pelas gerações anteriores, já que há, hoje, uma diversidade de formas de relacionamentos, que envolvem novos padrões. Atualmente adolescentes e mesmo pré-adolescentes "ficam", trocando beijos e carícias, categoria que inexistia, e que representa uma forma de relacionamento muitas vezes incompreensível para os adultos mais velhos. A vida sexual se inicia mais cedo, chegando-se à união conjugal com um maior conhecimento e experiência na área da sexualidade. $\mathrm{O}$ sexo é um tema mencionado mais abertamente do que costumava ser no passado e as primeiras experiências, por vezes, se dão dentro de um contexto de relacionamento amoroso, mas em outros casos ocorrem como curiosidade, como uma forma de obter prazer, independente de um compromisso formal.
$\mathrm{Na}$ atualidade, a forma de relacionamento aparentemente mais comum é o "ficar", sendo que o namoro parece não ser tão comum para os jovens - ou pelo menos se dando após uma fase em que se "fica" -, e tendo um significado diferente do que existia na geração de seus pais.

Neste trabalho buscamos estudar a adolescência, focalizando as concepções e vivências das relações amorosas de indivíduos neste período do desenvolvimento, pertencentes às chamadas "camadas populares" da cidade do Rio de Janeiro, o que se deu através da realização de entrevistas semi-estruturadas, visando a investigar o papel que tais relações ocupam na vida dos sujeitos.

A opção por este segmento social se deu pelo fato de a maior parte das pesquisas sobre o tema referir-se 
às camadas média/alta, e pela compreensão de que diferentes realidades socioeconômicas podem vir a influenciar vivências da adolescência. Além disso, observamos que maioria dos estudos desenvolvidos com classes populares aborda temas como violência, gravidez na adolescência, drogas e outros, sendo reduzidas as pesquisas sobre a questão das relações amorosas.

\section{ADOLESCÊNCIA}

O significado etimológico da palavra "adolescência" retrata bem o processo vivido nesta etapa da vida: do latim ad significa para, e olescer, crescer, referindo-se, portanto, ao processo de crescimento do indivíduo. $\mathrm{O}$ termo deriva também de adolescer, origem da palavra adoecer, fazendo com que estes significados indiquem a condição de crescimento físico e psíquico, que ocorre como um adoecimento, ou seja, com sofrimentos emocionais e transformações biológicas e mentais (Outeiral, 2003).

O conceito de adolescência, hoje vista como uma etapa natural do desenvolvimento humano, situada entre a infância e a idade adulta, é relativamente novo, já que, até o século XX, considerava-se que o indivíduo deixava de ser criança e passava diretamente à maturidade, sendo que essa transição era denominada apenas de "juventude" ou "puberdade", termos que se referiam unicamente às transformações físicas. $\mathrm{O}$ conceito de adolescência, que surge no período entre 1918 e 1939 (entre as duas Grandes Guerras), atualmente define uma etapa em si mesmo, e não um "caminho" entre duas outras, possuindo, desta forma, uma série de características peculiares. É, assim, uma época em que aspectos biopsicossociais são transformados, de maneira que o biológico, o psicológico, o social e o cultural são indissociáveis, sendo impossível analisar um independentemente dos outros (Osorio, 1992).

Knobel (1981), dentre os autores psicanalíticos estudiosos deste período do desenvolvimento, postula a existência de uma "síndrome normal da adolescência", cujos "sintomas" seriam a busca de si mesmo e da identidade, a tendência grupal, a evolução sexual manifesta, a separação progressiva dos pais, as oscilações do humor etc. Aberastury (1981), autora também de grande contribuição teórica, propõe que, durante este período da vida, o indivíduo realiza três lutos fundamentais: pelo corpo infantil, pela identidade e papel infantis, e pelos pais da infância. Caso estes lutos sejam realizados com sucesso, é possível ao adolescente ir em busca de uma identidade própria, não mais baseada exclusivamente nos conceitos e parâmetros parentais, mas também nas vivências e experiências do indivíduo. A identidade seria o sentimento de ser uma unidade separada dos outros, com uma continuidade, em que o indivíduo percebe ser o mesmo no passado e no presente (Osorio, 1992 e Knobel, 1981). Para Osorio, a aquisição da identidade seria o resultado da combinação entre "o que eu penso que sou", "o que os outros pensam que sou" e "o que eu penso que os outros pensam que sou".

Blos (1996) e Osorio (1992) postulam que a adolescência seria um segundo processo de individuação, que agora leva às relações objetais adultas, a partir do relativo desligamento dos objetos primitivos e da criação de novos vínculos com estes. Para que isso ocorra, é necessário que as relações parentais mais remotas tenham sido internalizadas como positivas, já que estas constituem a base dos futuros vínculos. A separação dos pais, que leva à individuação, não pode ocorrer sem que haja ansiedades frente à perda dos referenciais, e, para buscar suprir esse sentimento, o adolescente usa como novos modelos de identificação o grupo de iguais, adotado como uma "nova família", que fornece parâmetros de formas de pensar, agir, vestir, falar etc. antes proporcionados pelas figuras parentais.

Essa fase de intensas transformações é acompanhada por mudanças familiares, já que a presença de um adolescente altera todo o contexto familiar. Os pais muitas vezes mostram-se confusos com as "identidades transitórias" do filho que, ora batalha pela independência e por ser reconhecido como adulto, ora age com a infantilidade de uma criança pequena. $\mathrm{O}$ chamado "conflito de gerações" é necessário para que o jovem possa se sentir verdadeiramente uma pessoa separada dos pais, e os limites que estes impõem são importantes e desejados pelo filho, já que se opor aos mesmos é um indicativo da diferenciação. Se, na infância, a criança precisa da família para estabelecer relações objetais e originar instâncias psíquicas, na adolescência, é necessário que haja uma contestação de todos os seus referenciais, para que ocorra uma diferenciação, indispensável para que se passe à idade adulta. Os pais têm a complicada função de serem "espectadores ativos" (Knobel, 1981) das transformações do filho, acolhendo-o em seus momentos de extrema dependência, mas permitindo e incentivando uma independência moderada, adaptando-se a essa variação como a mãe se adapta a um bebê recémnascido.

A sexualidade é um elemento essencial para a adolescência, pois nesta etapa deve ocorrer o abandono da fantasia de bissexualidade e completude, para se assumir um papel sexual definido e, conseqüentemente, perceber-se "incompleto". Há, no entanto, pessoas que parecem relutar em assumir essa incompletude, mantendo-se narcisicamente à espera de um "príncipe" ou "princesa", alguém ideal, que na realidade não passa de uma projeção narcisista do próprio indivíduo. Para Outeiral (2003), é necessário, para o 
amadurecimento, que abandonemos a idéia do "príncipe" ou "princesa", e aceitemos o "sapo", ou seja, alguém possível e existente, imperfeito como nós. Ou ainda, enquanto na Antiguidade era preciso beijar o sapo para transformá-lo em príncipe, as novas gerações já querem o príncipe prêt-à-porter (Jablonski, 1998). Ocorre uma espécie de reedição do Complexo de Édipo, porém com um fato novo: agora o jovem é fisicamente capaz de realizar seus impulsos. Isso traz grande ansiedade, o que o leva a renunciar aos impulsos edípicos, desistindo das figuras parentais como objetos amorosos, buscando novos objetos amorosos fora da família.

Os relacionamentos amorosos na adolescência são uma espécie de "ensaio" para a vida adulta, e as experiências vividas podem ser vistas como maneiras de o indivíduo aprender a se relacionar e testar suas capacidades para tal, o que envolve "ficar", namorar, ter relações sexuais etc. Neste sentido, pode-se dizer que a vida amorosa e sexual dos adolescentes está inserida em um contexto global de busca pela aquisição de uma identidade.

O final da adolescência é caracterizado por vários autores (Osorio, 1992; Outeiral, 2003; Blos, 1996), de maneira semelhante, tendo como parâmetros a aquisição de uma maior estabilidade no que diz respeito à identidade, aos relacionamentos e ao humor, havendo ainda a possibilidade de escolher uma profissão, em busca da independência econômica, e a consolidação da sexualidade.

\section{AS RELAÇÕES AMOROSAS ATRAVÉS DOS TEMPOS}

Ao longo da história, podemos perceber como as concepções de sexualidade, amor e casamento são diretamente influenciadas por aspectos políticos, religiosos e culturais, sofrendo intensas mudanças em períodos relativamente curtos, justamente devido a estes fatores.

$\mathrm{Na}$ Antiguidade, os povos hebreus, gregos e romanos possuíam uma visão do sexo como algo bom e desejado pelos deuses, porém desvinculado do casamento, que era arranjado pelos pais, visando a procriação de herdeiros (Socci, 1983). O início do Cristianismo veio modificar esse quadro, já que o casamento e a família passaram a ser desvalorizados, sendo a virgindade priorizada como atributo indispensável, considerada como garantidora do acesso à salvação após a morte (Vainfas, 1992). Aos poucos a Igreja Católica foi transformando seus conceitos, passando primeiro a aceitar a sexualidade dentro do casamento, ainda que condenasse o prazer carnal, e, posteriormente, entre os séculos XII e XIII, tornasse o matri- mônio um de seus sacramentos. Assim, de hostilizada e desvalorizada, a união monogâmica e indissolúvel passou a ser quase uma regra aos leigos, como o celibato era para o clero.

A Reforma Protestante, ocorrida no século XVI, veio retirar parte do domínio da Igreja Católica sobre certos conceitos. Assim, o sexo conjugal tornou-se amplamente aceito e houve a rejeição da idéia da castidade como um desejo divino, apesar de o prazer permanecer considerado como algo errado. O casamento, valorizado, deixou de ser visto apenas como um sacramento, dentro dos domínios da Igreja.

No final do século XVIII e início do XIX surgiu o chamado "amor romântico", em que a compatibilidade psicológica passou a ser extremamente valorizada, havendo a idéia de que um cônjuge completava o outro. No entanto, a sexualidade permanecia relegada a um segundo plano, privilegiando-se a idéia do "amor sublime" (Giddens, 1993). Ainda no século XIX, a era vitoriana relaciona sexualidade com excreção, considerando-a como algo impuro e repulsivo (Socci, 1983).

O século XX foi o palco de intensas mudanças, no que diz respeito aos conceitos de sexualidade, amor e casamento, e isso se deu devido a alguns fatores históricos, dentre os quais podemos destacar: a Primeira Guerra Mundial, que colaborou para uma maior liberdade sexual, devido ao medo da proximidade da morte, que alimentou a mentalidade de se ter prazer imediato; o advento da Psicanálise, que trouxe a discussão acerca da sexualidade, inclusive em crianças, considerando o prazer sexual como necessário e saudável, e não condenável como antes; e o desenvolvimento dos meios de comunicação, que fizeram com que informações circulassem de maneira mais rápida, através de telefone, jornais, revistas e filmes.

Além disso, tivemos o movimento feminista, iniciado no século XIX, que se consolidou definitivamente no século seguinte, tendo importantes vitórias, como o voto e a emancipação financeira, que fez com que a mulher pudesse lutar por seus direitos de forma mais livre, não dependendo mais de um marido que a sustentasse. A sexualidade, desta forma, tornou-se mais espontânea e permitida, e a maternidade fora do casamento passou a ser uma possibilidade. Surgiu também o controle da gravidez, que contribuiu para a desvinculação entre sexo e reprodução.

A Revolução Industrial, também no século XIX, promoveu um afastamento do lar através do trabalho fora de casa e das escolas para os filhos, fazendo com que a mulher perdesse parte de sua função unicamente doméstica e passasse a exercer atividade laborativa fora do lar. Essa grande mudança iniciou o processo de separação entre sexo e reprodução, que abalou o ideal de casamento monogâmico e fiel. Assim, tornou- 
se aceitável o recasamento, já que o amor podia não ser eterno.

O amor é atualmente visto como fundamental para um relacionamento conjugal satisfatório, sendo considerado condição primordial para casamentos ocorrerem. As uniões conjugais e as relações amorosas, em geral, envolvem o companheirismo, a igualdade, o sexo e a procriação, de forma que o fim do amor é uma condição justa, especialmente entre as mulheres, para o término do casamento. Com isso, o número de divórcios aumentou, tendo ele sido oficializado na grande parte dos países ocidentais (Féres-Carneiro, 1998; Jablonski, 1998).

\section{AS NOVAS RELAÇÕES AMOROSAS}

Dentre as novas formas de relacionamentos amorosos, especialmente no que se refere a adolescentes, há uma que, a partir da década de 1980, vem tornando-se cada vez mais comum: o chamado "ficar". O "ficar" é algo que, por ser relativamente recente, ainda não foi completamente assimilado e compreendido por todos, como são outras relações mais tradicionais, como o namoro, noivado e o casamento. Tem como característica essencial a falta de compromisso entre os membros do casal, que busca obter prazer, a partir do exercício da sedução. O grau de envolvimento pode ir de uma simples troca de beijos e abraços até uma relação sexual, sendo que esta não necessariamente ocorre. Assim, há espaço para uma intimidade, mas mantém-se, ao mesmo tempo, um relativo afastamento.

Chaves (1993) define o "ficar" como um tipo de relação que independe de qualquer outra, ou seja, não está vinculado a um conhecimento prévio da outra pessoa, a um namoro, amizade etc., existindo por si só, sendo organizado por princípios, estando presente de maneira frequiente entre os jovens. No entanto, apesar de ser classificada como uma relação "normal" no discurso de adolescentes, é, para muitos, algo considerado "estranho", e "esquisito", exatamente pela característica do desenvolvimento de um contato relativamente íntimo, pontual em um dia ou uma noite (ou mesmo de forma mais prolongada), e no qual não há a necessidade de ver a outra pessoa novamente, não havendo nada que vincule o casal.

$\mathrm{O}$ "ficar" pode ocorrer tanto partindo de um desejo claro e explícito de um ou de ambos, como impulsivamente, como descarga, como uma vontade superficial, muitas vezes incentivada por amigos em situações específicas. Neste caso, pode acontecer em uma festa, por exemplo, sem uma vontade anterior, por insistência de outros, e nunca mais as duas pessoas terem qualquer tipo de contato ou relação. Desta forma, o que importa é o momento, e não as consequiências dele, sendo que a ação tem papel fundamental neste código de relacionamento cuja falta de compromisso é um incentivo para um maior desembaraço na tentativa de conquistar uma outra pessoa.

Independente de sua duração, que é variável, o que é mais ou menos permanente é a característica da ausência de compromisso formal, da transitoriedade, motivo pelo qual "ficar" com mais de uma pessoa em apenas uma noite, por exemplo, não seria visto como uma transgressão.

Chaves (1993) enumera vários motivos que levam os jovens a relacionarem-se dessa forma. É possível que o objetivo seja a diminuição da carência, evitando-se a solidão, podendo ainda ser um mero passatempo, uma brincadeira, quando não há "nada melhor 
para se fazer". "Ficar" pode ser uma forma de conhecer alguém melhor, de "incrementar" uma amizade, ou tornar uma conversa mais agradável, de ampliar a sociabilidade, levando a um certo aprendizado no modo de interação com o outro, além de ser também uma maneira de aumentar a auto-estima, especialmente quando o que importa é a quantidade e a aprovação do grupo. Pode ter como objetivo manter o contato com alguém de quem se gosta, por exemplo, um(a) ex-namorado(a), sendo também uma espécie de ponte para um futuro relacionamento. O "ficar" pode estar a serviço de uma busca pelo esquecimento de um outro relacionamento frustrado, ou mesmo pode ser um meio de quebrar a rotina de um namoro. No "ficar", a autora percebeu que é permitido, tanto aos homens como às mulheres, a tomada da iniciativa, apesar de não haver dentre os sujeitos um consenso em relação à atitude mais ativa por parte da mulher, considerada por muitos um ato vulgar.

Para Chaves (1993), este código de relacionamento ganha sentido na sociedade urbana contemporânea, já que o que está em jogo é a auto-satisfação e a evitação da frustração que poderia decorrer de um compromisso afetivo com o outro, que torna-se "descartável". Assim, o "ficar" é classificado por ela como beirando a "anti-paixão", quando comparada com o amor romântico, que implica em um envolvimento afetivo, e com a paixão, carregada de sentimentos em relação a um outro.

Mello (1996) contesta essa contraposição entre o "ficar", que seria um ideal narcísico, e os ideais românticos, afirmando que esse tipo de relacionamento envolve aspectos de ambos, sem que um exclua o outro e sem que haja uma contradição. Seu estudo, realizado através de questionários com jovens com idade entre 15 e 20 anos, teve como temas centrais as noções de compromisso e descompromisso e os modelos de relacionamentos associados a cada uma. A autora conclui que o "ficar" envolve a experimentação, utilizando métodos narcísicos para se atingir objetivos românticos, ou seja, teria como função a escolha de um "parceiro ideal" para um possível namoro futuro. Assim, em vez de haver uma total despreocupação com o outro, agindo-se de maneira imediatista, pode-se pensar no "ficar" como uma forma cuidadosa de programar o futuro. É, ainda, um meio de tentar evitar o sofrimento provocado pela frustração de uma relação em que os ideais românticos não conseguiram ser atingidos: "reinam os interesses narcísicos sobre o temor do fracasso de objetivos românticos" (Mello, 1996, p. 89).

\section{MÉTODO}

\section{Participantes}

Interação em Psicologia, jan.jjun. 2005, (9)1, p. 21-33
Participaram do estudo de campo um total de dez adolescentes das camadas populares cariocas, cinco do sexo feminino e cinco do sexo masculino, com idades entre 13 e 17 anos. Todos os sujeitos eram membros de um grupo de Capoeira com sede no centro do Rio de Janeiro.

\section{Procedimentos}

Tendo sido solicitado aos participantes que assinassem o "Termo de consentimento livre e esclarecido", foram realizadas entrevistas semi-estruturadas individuais, gravadas e transcritas, cujo roteiro invisível contemplava os seguintes temas: concepções de namoro e relações afins ("ficar", "casos"); expectativas sobre relacionamentos afetivos, envolvendo formas de conquista do parceiro desejado; concepções sobre a adolescência, incluindo relacionamentos familiares e sociais, e percepção de mudanças ocorridas; crenças e expectativas sobre casamento e constituição de família; vivências de sexualidade. Os sujeitos foram identificados pelas iniciais " $F$ " (feminino) e "M" (masculino) e enumerados.

\section{ANÁLISE E DISCUSSÃO DOS RESULTADOS}

A partir do material obtido foram construídas as seguintes categorias de análise: ficar x namorar; concepção de amor; o que é preciso para um relacionamento dar certo; virgindade e sexo; gravidez; início da adolescência; final da adolescência; diferença entre gerações.

\section{Ficar $\mathrm{x}$ namorar}

Sobre ficar ou namorar, os sujeitos deram os seguintes depoimentos:

"Geral agora, é coisa do momento, ver todo mundo ficando... Principalmente ficar, pra ver como é que é, aí que vem o namoro,... Ah, pra saber se é bom, pra saber se a garota é na moral, é maneira... Aí começa ficando... Aí se for compatível...começa o namoro..." (M3).

"Pelo menos assim, as pessoas que eu convivo mais, no colégio, claro, pra começar, o pessoal tá curtindo mais ficar, entendeu? Esse negócio de namorar... tá certo, tem muitos que namoram, muitos, muitos. Mas o pessoal tá curtindo mais ficar, sabe..." (F1).

Os entrevistados foram unânimes em afirmar "ficar" é a forma de relacionamento mais comum na atualidade, mostrando ser este um código presente nas classes populares, e não exclusivo das camadas média e alta da população, como indicou a pesquisa de Chaves (1993). 
Ambos os grupos diferenciaram dois tipos de "ficar": um que se constitui apenas como uma relação passageira, mais superficial, e outro que leva ao namoro. O primeiro foi descrito pelos sujeitos como ocorrendo em situações específicas, como festas, sem que houvesse um desejo anterior, podendo o casal não se ver ou falar novamente:

"Como não tem o sentimento... Beijo, entendeu... Se for bonita eu me mostro pra todo mundo que eu fiquei com ela, entendeu... Não tem aquele interesse, não tem aquele interesse... Eu fico só por ficar, entendeu... Mas também só..." (M1).

"...Se você for numa festa, você conhece um carinha, fica com ele, dá uns dois, três beijos nele, depois vai embora, se souber o nome dele é bom, se não souber... tanto faz..." (F4).

A outra maneira de "ficar" foi citada por todos os sujeitos como sendo um período de conhecimento, que pode levar a um namoro:

"Uma coisa muito normal, entendeu, é tipo, como se fosse pré-requisito para o namoro, é ficar, entendeu... pras pessoas saberem se elas querem mesmo ou se é só um relacionamento passageiro ou se é uma coisa mais séria, entendeu?" (M1).

"Assim, você tá num lugar, aí você viu uma pessoa... gostou, começou a ficar afim... Aí, tá, você consegue ficar com aquela pessoa... Aí passa um tempo, começa a namorar..." (F3).

Os entrevistados expressaram a idéia de que os relacionamentos amorosos na adolescência consistem em um "ensaio" para a vida adulta, já que percebemos nos seus discursos que "ficar" pode ser uma maneira de conhecer a outra pessoa ou "esperar a pessoa certa", para então manter um relacionamento "sério", mais formal, tendo, portanto, um objetivo final romântico:

"Quando a gente tá ficando, é porque a gente não tá seguro do que a gente quer... Às vezes o garoto fica meio assim, pensando: 'será que é a hora de eu chegar e pedir em namoro?'... Sabe... Aî', pô, continua ficando pra ter certeza se ela é fiel, se ela ta gostando mesmo de você... Acho que ficar é isso... Ter certeza do que a outra pessoa quer, e do que você quer..." (M3).

"Claro, se pintar um clima maior, uma coisa assim, pode namorar, continuar, tudo mais... Mas acho que o pessoal tá curtindo mais ficar mesmo, enquanto não aparecer, enquanto não aparece a pessoa que quer mesmo, assim... Aí vai ficando...” (F1).

\section{Amor}

O amor foi descrito pelos sujeitos da seguinte forma:
"Ah, quando tá pintando uma coisa forte, uma emoção assim mais forte, que eu tô sentindo por ela... Um ciumezinho, assim, não sei... Não que seja aquele ciúme forte, sabe... A pessoa percebe quando está gostando da outra pessoa..." (M2).

"Do nada... Assim, você tá num lugar, aí você viu uma pessoa... Pô, gostou, começou a ficar afim... Aí, tá, você consegue ficar com aquela pessoa... Aí passa um tempo, começa a namorar... Aí o amor não vai pintar assim, de uma hora pra outra... no início você vai só estar afim... Depois você vai começar a gostar, que é uma coisa que você gosta de muitas coisas, entendeu..." (F3).

Assim, o amor foi concebido pelos entrevistados como um sentimento que inclui maior envolvimento, iniciando-se a partir de um outro, especialmente para as meninas, o que é postulado por Outeiral (2003) como um desenvolver-se de forma gradual.

No entanto, discursos como o de F1 mostram um certo grau de idealização, que, para o autor, é próprio da paixão, quando fala sobre fazer tudo pensando em uma outra pessoa:

"Ah... Você quer estar com aquela pessoa, você pensa muito nela, você faz muita coisa pensando naquela pessoa. Quase praticamente tudo o que você faz, você pensa primeiro naquela pessoa, se isso é bom pra ela, pensa em formas de estar com aquela pessoa, entendeu? Não quer estar longe a nenhum momento..." (F1).

As concepções dos sujeitos correspondem aos ideais do amor-romântico iniciados no final do século XVIII e início do XIX, referentes à valorização das emoções e da compatibilidade psicológica, consideradas como itens essenciais para um relacionamento amoroso (Féres-Carneiro (1998).

\section{O que é preciso para um relacionamento dar certo}

Quanto ao que é necessário para o sucesso de um relacionamento, todos os sujeitos citaram confiança, fidelidade e sinceridade como importantes, e a traição como algo negativo:

"Primeiramente confiança... Com certeza absoluta, confiança... Esse negócio de beleza é um negócio que não tem muita coisa a ver. Agora, principalmente confiança, é você poder acreditar em mim e eu poder acreditar em você, e até às vezes esquecer do mundo, entendeu..." (M1).

"As duas primeiras coisas: tem que ter respeito e fidelidade. Porque eu acho que uma das piores coisas em um namoro é uma pessoa trair a outra pessoa." (F2).

Estes dados confirmam o que Zagury (1996) constatou quando fez a mesma pergunta. Confiança 
mútua e fidelidade foram apontados pela maior parte dos sujeitos por ela estudados. Outeiral (2003), ao se referir ao amor, ressalta que o mesmo implica o respeito pelo outro.

O amor foi também um dos aspectos mais citados por alguns de nossos sujeitos para que um relacionamento seja bem sucedido:

"Pra mim,... teria que os dois estar se gostando, se amando mesmo, pra dar certo..." (M2).

"Ah, sinceridade, amor, se não amar não tem jeito, não vai ficar junto nunca... É... Afinidade entre as pessoas... ser verdadeiros um com o outro, nada de mentira,... É isso, fidelidade, amor, ser verdadeiro um com o outro. Um pouco de paixão também é bom..." (F1).

Como ressaltamos em pesquisa anterior (FéresCarneiro, 1998), não se pode conceber hoje o casamento sem amor, assim como a falta deste leva ao desejo de separação.

\section{Virgindade e sexo}

A maior parte dos sujeitos entrevistados encontrase na etapa da "adolescência média", entre os 14 e os 17 anos, período em que, além das transformações corporais, já aparecem questões relativas à sexualidade, o que se fez presente na fala dos entrevistados.

É importante assinalar que, entre as meninas, apenas uma não era mais virgem, sendo esta a que teve o relacionamento amoroso mais duradouro, de quatro anos, com um namorado. Já no grupo masculino o que se verificou foi o inverso: apenas um sujeito disse ainda ser virgem, sendo ele o mais novo de todos os entrevistados, com 13 anos.

O grupo feminino mencionou uma ligação estreita entre sexo e sentimentos, enquanto entre os meninos, apenas um o fez:

“...Eu acho que não tem que estar... estar... tipo assim, ficando com qualquer um, transando com qualquer um porque acha 'ah, eu tenho que perder a virgindade'. (...) Pô, cara, primeira transa e primeiro beijo, a gente leva pro resto da vida. Então não tem que transar com qualquer um só pra perder a virgindade. Tem que esperar, cara, o momento certo..." (F1).

"Eu acho que pra fazer sexo com uma pessoa, não tem que fazer por prazer, acho que tem que gostar da pessoa... (...) Assim, deve ser estranho você não gostar de uma pessoa e fazer sexo com ela... Pode até rolar, mas não sei...” (F2).

"Quando tem sentimento sai muito melhor as coisas, sabe... (...) A hora certa eu acho que é fazer com a pessoa que você gosta, não importa o lugar, se é rua, hotel, corredor... Porque eu acho que fica tudo diferente... Fica totalmente diferente as coisas..." (M1).

Estes resultados confirmam aqueles encontrados por Heilborn (1999), nos quais as meninas mostraram preocupação com a escolha do parceiro e planejamentos sobre a iniciação sexual, para a qual o amor foi descrito como essencial. Os dados são, ainda, semelhantes aos de Fiúza (1990), que estudou jovens das camadas médias da população, que consideraram o sentimento como necessário para o ato sexual, o que o autor indica como representando um ideal mais tradicionalista.

"Lance de casamento... Eu acho que esse negócio de casamento é muito do fundamento do lugar, eu acho que acontece isso muito em alguns países... Ou religiões... só pode tirar a virgindade depois que casar... Eu acho que não tem isso, o corpo é da pessoa, a hora que ela achar que tá certo, entendeu..." (M1).

Os sujeitos mostraram concordar com a idéia sobre virgindade originada com o movimento feminista, iniciado no século XIX, em que a mulher não precisaria mais ser virgem para casar, gozando de uma sexualidade mais livre e espontânea, inclusive vendo como possível, em alguns casos, a maternidade fora do casamento. Este tipo de pensamento está em consonância com os dados encontrados por Jablonski (1998b), segundo os quais os jovens universitários não consideram a virgindade essencial para o sucesso de um casamento; assim como com aqueles obtidos por FéresCarneiro (1999), indicando que sujeitos de diferentes faixas etárias consideraram a virgindade sem importância e até podendo prejudicar os relacionamentos, tendo em vista a falta de experiência anterior. Por outro lado, as pesquisas realizadas por Jablonski, com jovens universitários cariocas têm apontado a existência de um ainda grande contingente de virgens, principalmente de moças $(36,41$ e $26 \%$ das amostras, coletadas em 1989, 1993 e em 2003 respectivamente, junto a universitárias de distintas faculdades do Rio de Janeiro e com idade em torno dos 19 anos). O que significa que parcela substancial de nossa juventude ainda confere à perda da virgindade feminina uma importância capital, ainda que estes dados não sejam muito divulgados junto aos meios de comunicação de massa (Jablonski, 2003). Isto pode ajudar a explicar o apurado no presente trabalho, onde apesar de a virgindade não ser considerada uma necessidade, uma mulher que tenha relações sexuais com muitos homens também não é desejada pelos garotos:

"Também, você nunca vai querer uma garota que já saiu com deus e o mundo... Mas, pô... É importante, mas não é aquela coisa necessária... Hoje, por exemplo, você não casa com uma garota só porque... Ela sendo virgem..." (M3). 
A diferença de gêneros se mostrou presente em nosso estudo, quando os entrevistados referiam-se à virgindade e sexo. Os sujeitos de ambos os sexos indicaram haver uma distinção entre a visão que se tem de uma mulher que "fica" com muitos, ou que tem relações sexuais na primeira "ficada", de um homem que faz o mesmo, sendo que, enquanto a mulher pode ficar "falada" ou pode ser considerada "galinha", o homem passa a ter uma "reputação".

"Não sei, eu creio que pra mulher seja diferente essas coisas... Não sei, deve pensar mais em sentimento antes de fazer as coisas..." (M1).

"Algumas pessoas que gostam de ficar com garota virgem, porque de repente aquela pessoa não é falada... 'Ah, ela não é virgem, isso e aquilo outro'... Tem outros que nem ligam. Depende. Assim, no caso, eu estando gostando dela, vou ficar com ela assim mesmo..." (M2).

"Geralmente é vista como galinha, que não presta ...Pô, a mulher, na primeira noite... Já vi uns caras falarem assim: 'fiquei com ela, na primeira noite, ela já...'...geralmente não fica uma visão muito boa... O homem, cara... A visão dele é totalmente diferente da nossa, porque pra eles, eles vêem isso como um troféu, entendeu... (...) A mulher leva uma fama totalmente inversa à do homem... pra mulher não, pra mulher é uma fama ruim, de que não presta, essas coisas..." (F1).

Em que pese o impacto das mudanças surgidas a reboque do movimento de emancipação feminina, ainda presenciamos uma situação díspar entre homens e mulheres no que tange a direitos, obrigações, oportunidades de ascensão social e liberdade nas ações e nos comportamentos. Mulheres ainda ganham menos do que os homens, têm menor presença entre os quadros políticos dirigentes, se dedicam mais aos trabalhos dentro do lar (mesmo quando marido e mulher têm uma dupla carreira) e ostentam menor liberdade quando o tema é a sexualidade, entre outras diferenças.

\section{Gravidez}

Quando perguntados sobre gravidez, a maior parte dos sujeitos, masculinos e femininos, mostrou-se contra a mesma na adolescência, especialmente por dificuldades financeiras para sustentar um filho:

"Gravidez... Quando você é jovem, como eu, assim, não é legal você ter um filho... Porque você tem que criar, e tudo mais... Não é o momento certo, é bom você ser formado, ter um padrão de vida melhor, pra depois ter um filho e poder dar pra ele o melhor... Até melhor do que você teve... Eu acho isso... É uma coisa legal, mas que tem que estar no momento certo..." (M3).
"Porque a pessoa (adolescente) é burra, porque não trabalha... às vezes não tem juízo, não trabalha, mora com os pais e não tem nenhuma renda dela mesmo, aí vai, fica grávida, tem filho e perde toda a adolescência dela criando filho" (F4).

\section{Início da adolescência}

Os entrevistados posicionaram-se assim em relação ao início da adolescência:

"Forma de pensar... Agir, em algumas coisas... (...) Assim, por exemplo, em relação a uma garota... Você muda seu pensamento em trabalho... Ver que a vida não é só brincadeira, você começa a pensar em outras coisas... Em vez de você ficar pensando no pai pra pegar dinheiro, na mãe pra pegar dinheiro... Você começa a ver, na adolescência, que não é bem assim, que pra ganhar dinheiro precisa de uma batalha, e tudo mais...” (M3).

"Pra mim a adolescência começou a partir dos... 14 anos, assim... Que meus pais deixaram eu sair mais... É... Tipo assim, eu poder sair de noite, e poder voltar de manhã, e falar: 'ó, mãe, tô chegando tal hora', mas eu procurei ganhar aquela confiança primeiro..." (F3).

"O nosso corpo começa a mudar... Vem a menstruação, começa a nascer os seios, bunda começa a crescer, perna começa a engrossar... Essas coisas..." (F2).

As respostas dos entrevistados condizem com os conceitos de adolescência definida como uma fase de transformações biopsicossociais. Assim, há mudanças na relação com os pais, novos interesses (sair com amigos, por exemplo), além de alterações corporais. Desta forma, as opiniões emitidas pelos sujeitos confirmam o conceito de "síndrome normal da adolescência”, proposto por Knobel (1981), já que eles se referem a novos aspectos relativos à sexualidade, que antes não eram observados, além de uma nova maneira de se relacionarem com os pais, que passa a envolver uma maior liberdade, porém com cobranças de responsabilidades.

A fala de duas entrevistadas, relacionada ao fato de os pais ainda as considerarem como crianças, condiz com a instabilidade citada por Aberastury (1981), em que o adolescente ora mostra uma extrema dependência, ora aparenta ser independente, o que gera nos pais uma confusão relativa a como tratar os filhos. O mesmo pode ser visto sob o referencial de Blos (1996), que afirma que, no processo de individuação adolescente, a representação objetal dos pais ora é a infantil, ora mais madura, fazendo com que o jovem se relacione com os mesmos de diferentes maneiras:

"Muda que você quer sair mais, quer sair sozinha, e a tua mãe ainda tá ali como se você ainda fosse uma 
criança mesmo... (...) Não é bom você perder a confiança, fazer algo que ela não gostou...” (F2).

“...A mãe continua chamando de criança... Antigamente só podia ir a algum lugar e chegar antes das 10, agora não, pode chegar de manhã... Tem que ter uma hora para voltar, mas não antes das dez... que é normal... Minha mãe começou a me liberar depois que eu fiz 15 anos..." (F4).

\section{Final da adolescência}

Sobre o final da adolescência, os sujeitos disseram:

“Ah... trabalhar... Quando você começa a trabalhar sério... às vezes quando você já tem um filho pra criar, a adolescência fica meio abalada... Você tem mais responsabilidades, mais deveres pra fazer... Eu acho que a adolescência, assim, acaba, mas a juventude não...” (M3).

"Quando você começa a trabalhar, a ter que se sustentar, ter que pagar aluguel, conta de luz, de água, conta de não sei o que mais... aí você passa a ser já uma pessoa adulta...” (F4).

Todos os entrevistados dos dois grupos caracterizam o final da adolescência como marcado por maior responsabilidade, especialmente relacionada à aquisição de um emprego e à possibilidade de auto-sustento, o que condiz com os aspectos citados por Osorio (1992) e Outeiral (2003).

\section{Diferenças entre as gerações}

A diferença mais apontada entre a geração dos pais e a dos entrevistados foi o fato de hoje terem maior liberdade, tanto em relação ao "ficar", que não existia antigamente, como em relação ao sexo, que no passado só ocorria após o casamento.

"Antigamente a coisa era muito mais 'vou arranjar uma namorada e fico a vida inteira com ela'. Hoje não tem mais isso. Hoje é sair, zoar... Os pensamentos tão diferentes...” (M1).

“Antigamente (sexo) só depois de casado... Porque tinha que casar com quem seu pai mandava, às vezes nem gostava dele e nem conhecia... A minha mãe não podia sair sozinha até 20 anos... já eu não sou assim, eu saio sozinha, e namoro sozinha, fico com alguém sozinha, já ela não podia fazer isso... Os pais vão ficando mais liberais, antigamente não era assim..." (F4).

Apesar dessas diferenças, a maior parte das jovens referiu-se a uma certa compreensão, por parte dos pais, sobre as novas formas de relacionamento:

"Ela entende, porque se ela é liberal... ela queria também ser assim, mas não pôde.” (F4).

"Não, eles entendem, eu falo: 'pai fiquei com fulano, mãe fiquei com siclano', aí eles: 'ah legal, mas não é namoro?' 'Não sei, vou ver, estou pensando ainda'..." (F5).

Esta compreensão por parte dos pais demonstra um aparente sucesso no cumprimento do papel de "espectadores ativos", como propõe Knobel (1981). Assim, mesmo não tendo vivido a experiência de "ficar", quando jovens, buscam adaptar-se à realidade em que seus filhos vivem, e que é comum aos adolescentes de hoje.

\section{O que fariam com os filhos igual ao que os pais fizeram com eles}

Em relação a repetir ou não o comportamento dos pais, os sujeitos responderam:

"Eles (pais) têm medo do que as outras pessoas vão fazer (com os filhos), entendeu... Aí fica chatão... Eu penso assim: eu teria a mesma preocupação que eles têm... Eu acho que quando eu tiver meu filho, assim, eu também vou ter preocupação, é muito sinistro..." (M3).

"Ensinaria (aos filhos) as coisas boas da vida... falava para ele (filho) qual é o caminho errado e qual é o caminho que ele deve seguir... Foi feito comigo, minha mãe me ensinou... caminho errado e caminho que tenho que seguir" (F4).

Os entrevistados afirmaram que terão as mesmas preocupações dos pais. Mostram ainda uma relativa maturidade, na medida em que, embora considerem "chatas" as cobranças dos pais, podem compreender os motivos dos mesmos e identificar-se com as figuras adultas.

\section{Planos para o futuro manifestados}

Sobre o futuro, estes foram alguns dos posicionamentos:

"É o que eu tava falando, sobre futuro, é... Preparar tudo cedo. Por exemplo, trabalhar muito, porque o mundo tá globalizado. (...) Meu sonho é ter uma boa faculdade, pra ter um bom emprego, pra ter uma boa namorada, pra ter bons filhos. Pra poder passar boas experiências, pra que eles possam passar pros filhos deles...” (M1).

"Quando chegar em 18 anos, chegar... é servir, ficar lá dentro até virar cabo, depois tenente, daí para frente seguindo carreira lá dentro... Depois de 18, daqui a pouco arranjar um emprego...” (M5).

"Planos pro futuro... Terminar os estudos... Quero me formar psicóloga... Ou eu queria me formar... Queria fazer duas faculdades, pelo menos eu pretendo... Psicóloga e astronomia. Astronomia ou astrologia, sei lá... Coisa que estuda as estrelas..." (F2). 
“Eu? Eu estou pensando... eu vou estudar para medicina veterinária, não vou casar agora, posso até morar junto, mas vou fazer minha faculdade agora, depois que terminar minha faculdade, vou casar, arranjar um emprego, ter um filho só...” (F5).

Como vimos pelos depoimentos, entre os planos para o futuro, a grande maioria dos adolescentes apontou em primeiro lugar o desejo de cursar uma faculdade, sendo que a totalidade referiu-se à necessidade de ter um emprego. Os itens citados relacionamse diretamente com alguns daqueles próprios do final da adolescência e relativas à entrada no mundo adulto, ou seja, capacidade de ter uma profissão e uma independência econômica (Osorio, 1992), independência dos pais e escolha profissional (Outeiral, 2003). Além disso, tanto na fala dos meninos como na das meninas, observamos a importância atribuída ao trabalho, sinalizando para a possibilidade de um casamento igualitário, em que ambos os cônjuges contribuem para a renda familiar.

\section{CONSIDERAÇÕES FINAIS}

Em nosso estudo, a forma de relacionamento citada pelos sujeitos como a mais freqüente na atualidade foi o "ficar", uma relação inicialmente sem compromisso, mas que funciona como uma espécie de "teste", para que se conheça uma outra pessoa, verificando-se se há afinidade, se é possível desenvolver um sentimento de amor, para, então, poder vir a namorar. Considerando que os entrevistados citaram como principais itens necessários para um relacionamento dar certo o amor, a fidelidade e a confiança, parece-nos que os jovens desejam se envolver afetivamente, ansiando por relações "verdadeiras", das quais buscam certificar-se através do "ficar", que seria uma forma de evitar uma decepção futura. A adolescência é uma época em que a insegurança se faz presente de forma marcante, e o indivíduo busca experimentar, ensaiar, testar, para que não se frustre facilmente. Esse código de relacionamento parece dizer respeito a essa experimentação, o que pode-nos levar a concluir que ele seja, muitas vezes, mal compreendido pelas gerações que não o vivenciaram, e que consideram-no apenas como algo passageiro, vazio de significado. Grande parte das meninas e alguns meninos entrevistados destacaram o fato de o namoro ser uma restrição, fazendo com que o indivíduo esteja "preso" a outra pessoa através de um compromisso. Talvez possamos pensar se o temor de nossos sujeitos é de serem prisioneiros de relacionamentos baseados somente em um comprometimento formal, sem a presença de "uma emoção mais forte", "uma atração maior" (como dois entrevistados se referiram ao amor). Desta forma, "ficam" com uma outra pessoa sem que haja um sentimento maior, mas só namoram quando este existe, o que nos parece uma posição mais autêntica do que a que víamos até o século XIX, quando amor e casamento eram coisas desvinculadas, sendo afeto e afinidade desprezados.

Os jovens por nós estudados podem ser vistos como românticos, pois estão à espera da "pessoa certa" para um namoro, relacionamento considerado "mais sério", e que, por isso, gera inseguranças, o que é evitado pelo "ficar", como um entrevistado apontou com clareza. Podemos, no entanto, nos perguntar se há alguém que realmente se encaixaria nessa classificação, ou se ela representaria uma figura idealizada, sem defeitos, que não levaria a qualquer frustração. Assim, essa espécie de "príncipe" ou "princesa" encantados corresponderia, na realidade, à mesma projeção dirigida aos pais da infância, que na adolescência transformam-se em "sapos", caindo de pedestais, com suas imperfeições vindo à tona, de forma que "a pessoa certa", pode ser vista como uma última esperança de haver alguém perfeito. Há aí uma idéia de alguém que será "a outra metade", completando o indivíduo como a mãe primitiva fazia, em um estado de fusão com o bebê, de maneira que, a partir do momento em que se assume essa completude como algo inatingível, é possível estabelecer relações objetivas adultas, o que se espera que ocorra no final da adolescência.

Os participantes de nosso estudo mostram alguns padrões e referenciais semelhantes aos de gerações anteriores, especialmente no que se refere à diferença de gêneros. Foi comentado por nossos sujeitos sobre a visão depreciada que se tem de uma mulher que "fica" ou tem relações sexuais com várias pessoas, enquanto o homem em situação similar é valorizado; falou-se sobre a maneira distinta como é concebida a virgindade masculina e a feminina, sendo a última considerada como mais importante; além disso, houve comentários sobre a posição feminina de esperar a iniciativa masculina, para não ser "mal vista" por outros indivíduos. Parece-nos que nossos adolescentes utilizam um código de relacionamento atual, porém mostram ter herdado parâmetros tradicionalistas, fruto de uma sociedade cuja diferenciação entre os gêneros muitas vezes privilegia o homem, a quem é permitido certas coisas que desvalorizariam a mulher. Duas de nossas entrevistadas mostram um rompimento com esse padrão ao afirmarem que são explícitas quando desejam "ficar" com alguém, sendo que apenas uma refere-se a uma ausência total de preconceitos nos dias de hoje.

Em nosso estudo, apenas um menino ainda era virgem, e, no grupo feminino, pelo contrário, somente uma menina por nós entrevistada já havia perdido a virgindade, e todas disseram considerar tanto a primeira relação sexual como as demais como algo importante, que deve ser feito com uma pessoa "especial", sendo contrárias a que ela ocorra na primeira vez que se "fica" com alguém. Há, portanto, ideais de compatibilidade e afinidade comparáveis aos propostos pela geração da chamada "revolução sexual", 
quando tais aspectos passaram a ser importantes para que o sexo e as relações como namoro e casamento ocorressem. Da mesma maneira, o fato de os garotos citarem a virgindade como algo que não é essencial, para que se relacionem, ou não, com uma garota, também reflete a herança da referida geração. A posição da totalidade dos sujeitos contra a gravidez na adolescência, especialmente devido à impossibilidade de sustentar um filho, também aponta para uma preocupação em relação ao sexo, diferente da irresponsabilidade muitas vezes atribuída ao indivíduo nessa fase do desenvolvimento. Assim, podemos considerar que os adolescentes de hoje não possuem uma visão sobre virgindade, sexo e gravidez totalmente oposta à de seus pais, ou mesmo avós, havendo, pelo contrário, um pensamento mais semelhante do que geralmente imaginaríamos. Nossos jovens não parecem querer apenas obter prazer a qualquer custo, mas desejam têlo, especialmente as meninas, com pessoas com quem possuem uma relação afetiva, sendo a "primeira vez" permeada por medos e expectativas.

Os adolescentes por nós entrevistados, como outros de diferentes épocas, querem sair, aprender coisas novas, descobrir, com a ajuda de seus pares, o que a vida pode-lhes oferecer, buscando distinguir o que é positivo do que pode lhes causar danos. Este é um momento em que o papel dos pais é crucial, no que diz respeito à imposição de limites, que servem como uma segurança para o jovem, mesmo quando são transgredidos. É importante que os genitores se dêem conta do quanto seus filhos cresceram, mas também de como ainda são imaturos, parcialmente com dificuldade de perceber coisas que podem lhes ser nocivas, encontrando um meio termo entre tratálos como crianças e vê-los como adultos maduros. Os limites, muitas vezes pensados pelos pais como possíveis causadores de "traumas", são essenciais e, mesmo quando criticados pelos adolescentes, são sentidos como uma forma de cuidado, de proteção, fundamental para alguém que passa por um período do desenvolvimento marcado por uma maior fragilidade. Podemos perceber isto na fala de nossos sujeitos, quando afirmam que darão aos próprios filhos a mesma liberdade que lhes é dada, ainda que se imaginem com preocupações semelhantes às que seus pais têm, sobre os locais que frequientam, suas companhias etc., demonstrando que, mesmo incomodados com o "controle" exercido pelos pais, este parece ser visto como algo positivo.

Os jovens que participaram do nosso estudo mostraram-se preocupados com seu futuro profissional e financeiro, sendo que todos indicaram como um plano importante a aquisição de um emprego, tendo muitos se referido a cursar uma faculdade, o que representa um dos aspectos que marcam a entrada na idade adulta. Esta preocupação também pode ser vista como algo que faz parte da vida desses adolescentes de maneira expressiva, já que alguns sujeitos citaram as dificuldades financeiras que suas famílias já enfrentaram e o desejo de não passarem por situações semelhantes. A respeito de casamento e formação de família, observamos através de nossas entrevistas o desejo, especialmente nas meninas, de uma união, formal ou não, com alguém, com o plano de ter filhos, sendo este um dos projetos de futuro da maioria delas, além de ter sido algo citado também pelos meninos. Novamente, pudemos constatar ideais que não contradizem as gerações anteriores, mas constituem-se como uma continuação dos valores das mesmas, o que parece indicar que os relacionamentos passageiros são nada mais do que buscas por uma pessoa, visando um futuro relacionamento mais duradouro.

Podemos concluir que nossos sujeitos não parecem desejar nada de tão diferente das gerações anteriores, como muitas vezes pensamos, sendo seus parâmetros e ideais muito semelhantes aos das mesmas, havendo, no entanto, a utilização de certos recursos surgidos apenas recentemente. Os adolescentes por nós estudados parecem, à primeira vista, possuir idéias opostas às dos próprios pais, utilizando o "ficar" como o código de relacionamento mais frequiente, desejando ter uma liberdade sem o controle parental, transgredindo, por vezes, limites, e tudo em busca de uma identidade própria, independente de seus genitores. Entretanto, por outro lado, mostram que internalizaram padrões transmitidos por aqueles de quem parecem divergir, como ideais de amor, namoro, formação de família, futuro, o que aponta para um rompimento em relação à família, que não se faz, porém, de maneira total. Assim, parece que podemos, de alguma forma, "confortar" os pais de adolescentes, que muitas vezes encontram-se "perdidos" no trato com seus filhos, já que nosso estudo pôde indicar o quanto seus valores foram passados com sucesso para os mesmos. Talvez seja importante, ainda, que seja lembrado a estes pais o quanto seus próprios genitores, os avós destes jovens, também devem ter-se alarmado à época em que eram eles os "rebeldes", o que, mais do que uma peculiaridade dos tempos atuais, compõe uma característica inevitável para a passagem à maturidade.

Comparando os dados obtidos com os de outros trabalhos (Chaves, 1993; Zagury, 1996; Fiúza, 1990), não nos parece haver diferenças significativas relacionadas à distinção de classes sociais. Como os adolescentes de outros segmentos sociais, nossos sujeitos encontram-se em um período de instabilidade, em que buscam a identificação com grupos de iguais, nos quais conseguem amenizar a insegurança causada pelo "abandono" dos pais da infância. Assim, saem, "ficam", namoram, desejam uma profissão, preocupamse com seu futuro, tal como os jovens dos segmentos economicamente elevados da população brasileira, 
sendo que talvez uma distinção esteja no fato de sua origem social ter-lhes feito passar por experiências de dificuldades distintas das dos últimos.

\section{REFERÊNCIAS}

Aberastury, A. (1981). O adolescente e a liberdade. Em Aberastury, A. e Knobel, M. (1981). Adolescência normal: um enfoque psicanalítico. Porto Alegre: Artes Médicas, 22-34.

Blos, P. (1996). A transição adolescente. Porto Alegre: Artes Médicas.

Chaves, J. C. (1993). "Ficar com” a individualização: um estudo sobre um código de relacionamento no Brasil. Dissertação de Mestrado. Rio de Janeiro: Departamento de Psicologia, PUCRio.

Féres-Carneiro, T. (1998). Casamento contemporâneo: o difícil convívio da individualidade com a conjugalidade. Psicologia: Reflexão e Crítica, V. 11, No 2, 379-394.

Féres-Carneiro, T. (1999). Conjugalidade: um estudo sobre as diferentes dimensões da dimensão amorosa heterossexual e homossexual. Em T. Féres-Carneiro, Casal e Família: entre a tradição e a transformação. Rio de Janeiro: Nau Editora, 96117.

Fiúza, S. (1990). Identidade jovem em camadas médias urbanas. Em Velho, G. (Org.) Individualismo e juventude. Rio de Janeiro: Programa de Pós-Graduação em Antropologia Social, UFRJ.

Giddens, A. (1993). A transformação da intimidade: sexualidade, amor \& erotismo nas sociedades modernas. São Paulo: UNESP.

Heilborn, M. L. (1999) Construção de si, gênero e sexualidade. Em Heilborn, M. L. (Org.) Sexualidade: o olhar das ciências sociais. Rio de Janeiro: Jorge Zahar, 38-51.

Jablonski, B. (1998). Até que a vida nos separe: a crise do casamento contemporâneo. Rio de Janeiro: Agir.

Jablonski, B. (1998b). Crenças e crendices sobre sexualidade humana. Psicologia: Teoria e Pesquisa, V. 14, nº 3, 209-218.

Jablonski, B. (2001). Atitudes frente à crise do casamento - Quem quer casar com a Dona Baratinha? Em T. Féres-Carneiro (Org.), Casamento e família: do social à clínica. Rio de Janeiro: Nau Editora, 81-95.

Jablonski, B. (2003). Afinal, o que quer um casal? Algumas considerações sobre o casamento e a separação na classe média carioca. Em T. Féres-Carneiro (Org.). Família e casal: arranjos e demandas contemporâneas. Rio de Janeiro/São Paulo: PUCRio/Edições Loyola, 141-168.

Knobel, M. (1981). A síndrome da adolescência normal. Em Aberastury, A \& Knobel, M. (1981). Adolescência normal: um enfoque psicanalítico. Porto Alegre: Artes Médicas, 24-62.
Mello, S. C. L. (1996). Românticos ou narcísicos? Um estudo sobre o descompromisso afetivo contemporâneo. Dissertação de Mestrado. Rio de Janeiro: PUC-Rio, Departamento de Psicologia.

Osorio, L. C. (1992). O adolescente hoje. Porto Alegre: Artes Médicas.

Outeiral, J. (2003). Adolescer: estudos revisados sobre adolescência. Rio de Janeiro: Revinter.

Socci, V. (1983). Elaboração e validação de uma escala de atitudes em relação ao sexo. Tese de Doutorado. São Paulo: USP, Instituto de Psicologia.

Vainfas, R. (1992). Casamento, amor e desejo no ocidente cristão. São Paulo: Ática.

Zagury, T. (1996). O adolescente por ele mesmo. Rio de Janeiro: Record.

Enviado: $12 / 12 / 2004$ Revisado: 02/04/2005 Aceito: 08/04/2005

\section{Sobre os autores:}

Mariana Matos: Mestre em Psicologia pela PUC-Rio.

Terezinha Féres-Carneiro: Doutora em Psicologia Clínica pela PUC/SP, Pós-doutorado em Psicoterapia de Família e Casal pela Sorbonne, Professora Titular do Departamento de Psicologia da PUC-Rio. Endereço eletrônico: teferca@psi.puc-rio.br.

Bernardo Jablonski: Doutor em Psicologia Social pela FGV/RJ, Professor Assistente do Departamento de Psicologia da PUC-Rio. 